\title{
Fusion Recognition Model and Control Strategy of Mobile Location Based on WAP and WLAN
}

\author{
Guang Chen ${ }^{1}$, Qingbo Sun ${ }^{2}$, Xiaohua $\mathrm{Wu}^{3^{*}}$ \\ ${ }^{1}$ School of Economics and Management, Jiangxi University of Traditional Chinese Medicine, \\ Nanchang, 330004, China \\ ${ }^{2}$ Arts Design Department, Jiangxi College of Foreign Studies, Nanchang, 330099, China \\ ${ }^{3}$ Modern Economics \& Management College, Jiangxi University of Finance and Economics, \\ Nanchang, 330013, China \\ xiaohua_wu2013@yeah.net \\ ${ }^{*}$ Corresponding author
}

Keywords: Electronic commerce, Multivariate, F test, PDA code, WAP, WLAN.

\begin{abstract}
In order to meet the demand of consumers shopping whenever and wherever possible to improve the enterprise's sales performance, based on the mode of WAP mobile phone online shopping and combined with the WLAN wireless local area network, this paper designs ecommerce marketing system. The system uses the form of PDA code to search for the consumer users, using F test and multivariate regression model carry out study on the user data, so the system has the automatic positioning function of target user, so as to realize the feedback regulation process of marketing strategy. For the trading company electric hardware system, tracking data statistics found that WLAN mobile e-commerce platform can effectively improve the mobile terminal sales performance based on WAP and the system is more stable, which provides technical reference for the study of electronic commerce.
\end{abstract}

\section{Introduction}

WAP mobile phone online shopping site has already expanded a larger range from the original "soit" and Wuhan Plaza [1]. With the continuous development and the technology matures of wireless local area network (WLAN) technology, its advantages are more and more familiar, people begin to pursue the communication and information services anytime anywhere [2]. Therefore, the introduction demand of WLAN technology has become increasingly urgent, and especially the WLAN technology will be applied to the electronic commerce, which not only improves the efficiency, but also reduces the use of human resources, making the electronic commerce is more modern, it brings people more convenient [3]. In order to improve consumers shopping needs whenever and wherever possible and improve the enterprise electronic commerce performance, this paper introduces the design of WLAN mobile e-commerce platform based on WAP, the main framework is show in Figure 1.

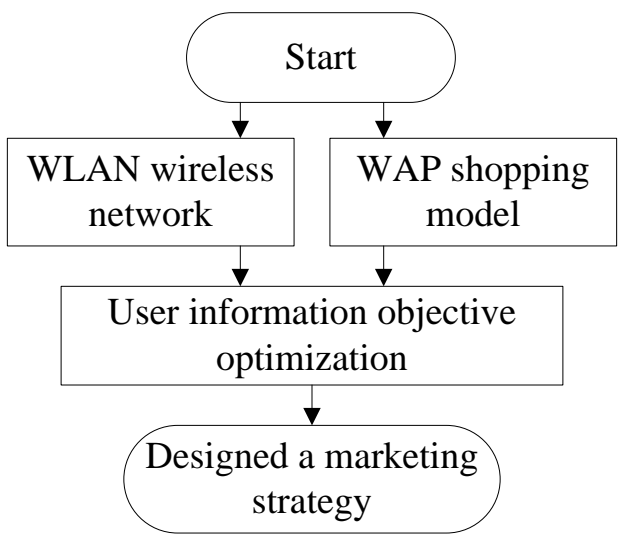

Fig.1: The basic framework of WAP sales platform based on WLAN 
Combined with WLAN and positioning technology, using the information fusion technology establishes the consumer target user positioning system of WLAN positioning information fusion [4]. Through the wireless network card, we scan all wireless routers on the positioning environment, which can access to each wireless router ID value, MAC value and RSSI value under the current environment. Through the objective optimization algorithm, it optimizes the RSSI value and compared with the information in the database according to ID value, and then extracting positioning router, finally positioning router RSSI value will be used for read positioning program, we can get the users consumer information [5]. When people obtain the users WAP information, we will understanding the user consumer orientation according to users' consumer dynamic data, and then through the information feedback regulation, we need to formulate the marketing strategy according to the customer.

\section{The Design of E-commerce Marketing User Goals Optimization Algorithm}

Supply chain management platform contains the user layer, data layer and the application layer of the three layer structure. It needs to be unified to COM display, so as to realize the interactive operation and share them with our components. User layer is in the client browser for HTML, with Scripting, Java operation,which is used to complete the user and application level of treatment results between the mutual communication, and interaction between data.All can be directly transferred to the requester of the corresponding database.Mainly on application layer,the data layer is to used to provide the data source.which mainly adopts distributed structure[6]. The application layer, is mainly used for the user layer application request related to treatment, to business data, calculations were completed, but also the data processing results feedback to the user. The use of XML technology to build enterprise supply chain management platform, which can not only meet the supply chain management system of three layers structure, but also includes the original enterprise ERP on platform of electronic business affairs and customer relationship management system integration. Figure 2 shows the chart of electronic commerce supply chain management.

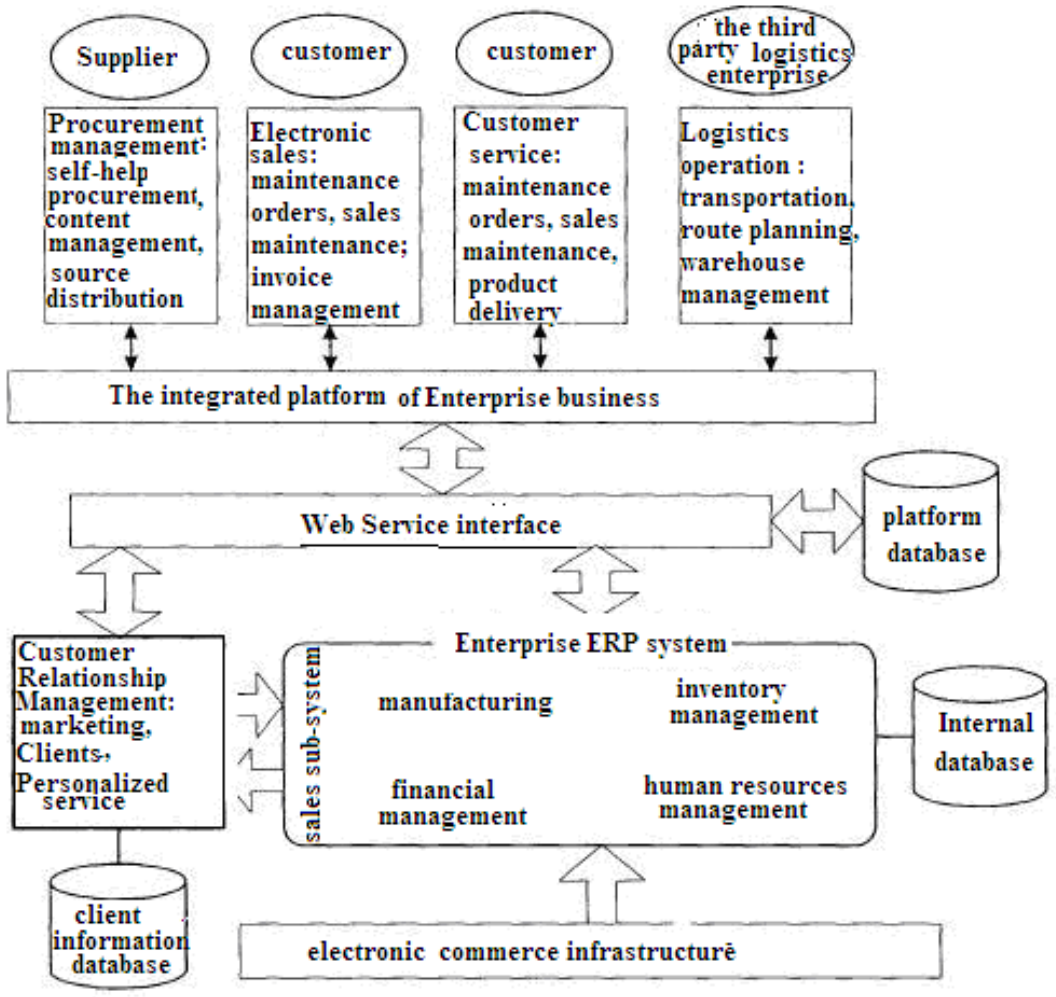

Fig.2: The chart of Electronic commerce supply chain management

The main research object of electronic commerce marketing strategy is the WLAN client consumer users[7]. In order to improve the efficiency of marketing, we must carry out target optimization on the WLAN client information. $P_{i}$ shows that has a user data set of similar or 
identical feature.

$$
P N_{1} \cup P N_{2} \cup \cdots \cup P N_{j}=\phi(i \neq j), P N_{i} \cap P N_{j}=P N .
$$

The user data is optimized by the heteroscedasticity, and according to multiple variables autoregressive conditional heteroscedasticity model, we can obtain the general form of simple error.

$$
\eta_{l}^{2}=\beta_{0}+\beta_{1} \lambda_{l-1}^{2}
$$

Among them, $\lambda$ shows the heteroscedasticity taking $\lambda_{l-1}$ change information as the conditions, because $\lambda$ goes throughout the process of the whole objective optimization, therefore $\lambda$ is associated with the error of a plurality of times, a general expression can be written as:

$$
\eta_{l}^{2}=\beta_{0}+\beta_{1} \lambda_{l-1}^{2}+\beta_{2} \lambda_{l-2}^{2}+\cdots+\beta_{q} \lambda_{l-q}^{2} .
$$

Where the test model of user optimization can be expressed as

$$
h_{l}^{2}=\beta_{0}+\beta_{1} \lambda_{l-1}^{2}+\beta_{2} \lambda_{l-2}^{2}+\cdots+\beta_{q} \lambda_{l-q}^{2}+u_{l} \text {. }
$$

We can use F test to determine the optimal significantly of aided multivariate regression model, and can also use $(n-q) R 2$ to test. In order to realize the automatic positioning of WLA client target consumer users, it can realize the optimization of the user information [8]. Using the form of PDA code searches the user, so that the main program is as follows:

PrivateSubFood_order ()

If Gnum='user 1' Then

Textl.Text=Textl.Text +

GPriee $=3$

EndIf

Else

If Gnum=' user 2 ' Then

Text2.Text $=$ Text2.Text +

GPr1ee $=4$

EndIf

Because the information network is formed, the development capacity and market development capabilities of enterprise products gradually formed the group product strategy and competition mode. Especially in the electronic commerce technology development process, the management method of traditional supply chain and seriously wasn't adaptive to the development of information technology[8]. Therefore, the supply chain management in many enterprises focuses on the center of market competition and the combination of modern information technology in the electronic commerce system based on supply chain management platform, in order to enhance their own competitive advantage.Now with the rapid development of network technology, based on XML technology,we built the company's supply chain management information system, but also for the enterprise has brought more convenient information transfer. Network technology has enabled the development of enterprise's information system structure has undergone more changes. Two levels of the structure are not sufficient to meet the diverse needs and the complexity of the application system of business process requirements, therefore, based on this and construct the user layer, data layer and the application layer of the three layer structure of information system. XML could not do not install any XML software generated by the database. The server generates a XML database in response to the program design[9]:

$<\%$

response. and Content the Type = "text or xml"

and set conn= the Server.Create the Object ("ADODB. the Connection") 
conn. the provider="Microsoft. the Jet.OLEDB.4.0;

conn.open the server. mappath("/db/ the database.mdb")

and sql=" select the First Name, the Last Name from Persons"

and set rs=Conn. the Execute(sql)

then rs.MoveFirst()

response. the write("<?xml the version='1.0' and encoding='ISO-8859-1'?>")

response. the write("<Customers $>$ ")

and while (not rs. the EOF)

response. the write("<Person $>$ ")

response. the write("<the FirstName $>$ " \& rs("the FirstName") \& "</ the FirstName $>$ ")

response. the write("<the LastName $>$ " \& rs("the LastName") \& "</ the LastName $>$ ")

response. the write("</Person $>$ ")

and rs.Move the Next()

then wend

rs. the close()

conn. the close()

response. the write("</Customers $>$ ")

$\%>$

\section{The Design of Mobile WAP Business System based on WLAN}

In order to verify the effectiveness and reliability of target optimization algorithm designed in the second part, this paper builds a target optimization platform of WAP consumer groups, and the use of WLAN network carries out positioning statistics on the shopping website login frequency of target user routing, in which the objective optimization process is shown in Figure 3.

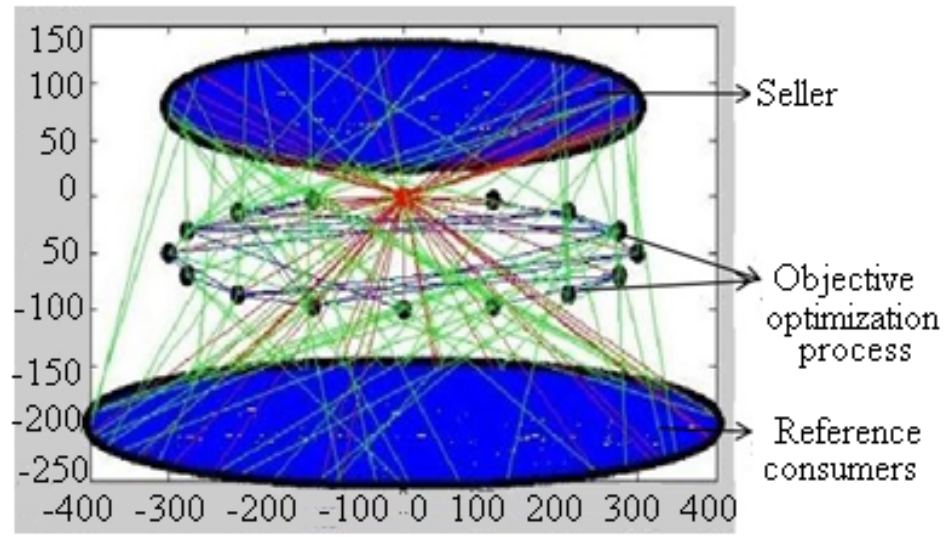

Fig. 3 The process optimization of consumer groups target user

Figure 3 shows the optimization process of the consumer groups target user in the system, the target optimization mainly refers the shopping information of consumption group [10]. Through the query of purchase data and WLAN flows use, we can get the target user that is closest to purchase commodity desires, and then give their feedback to the seller, setting the reasonable marketing strategy. 


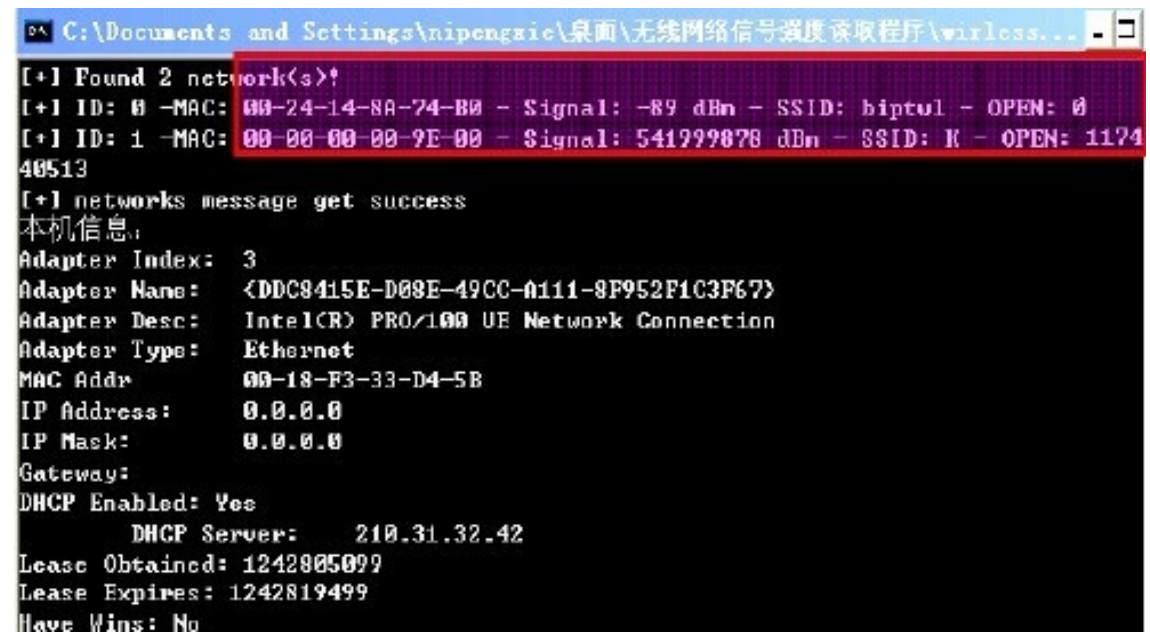

Fig.4: The process of user information positioning

As shown in Figure 4, wireless LAN usually goes through the software to access wireless signals information, which can get complete wireless router information, including RSSI value, MAC value, SSID and so on [11]. Through the visit of routing WAP websites, we obtain user the optimization distribution map of shopping information as shown in Figure 5.

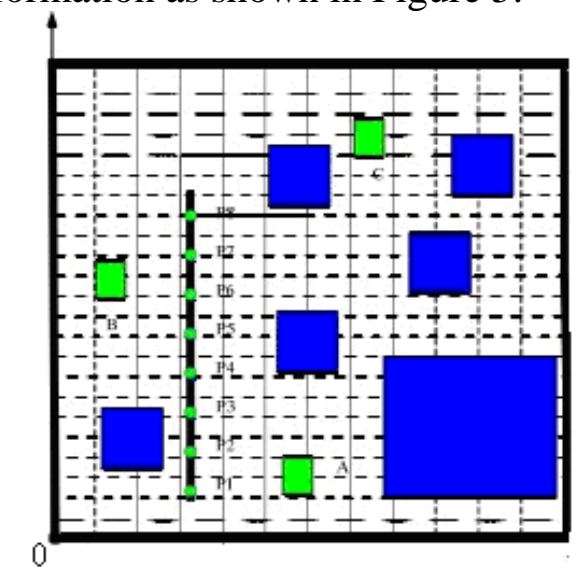

Fig.5: The optimization distribution of target user shopping information

Figure 5 shows the automatic positioning function of WAP electric system, when the use frequency of user is higher, it will be presented distinctly blue in the distribution, and when blue area is greater, indicating that the user's purchase desire is higher [12]. Therefore we can carry out regular visits, so as to realize the feedback regulation process of marketing strategy.

Table 1: The sales statistics of mobile electric strategy

\begin{tabular}{llllr}
\hline Time & $\begin{array}{l}\text { Normal } \\
\text { channels } \\
\text { sales } \\
\text { (million) }\end{array}$ & $\begin{array}{l}\text { Internet platform } \\
\text { sales (million) }\end{array}$ & $\begin{array}{l}\text { Mobile } \\
\text { commerce } \\
\text { (million) }\end{array}$ & $\begin{array}{r}\text { e- } \\
\text { sales }\end{array}$ \\
\hline $\begin{array}{l}\text { First } \\
\text { quarter }\end{array}$ & 10.21 & 4.23 & 6.28 \\
$\begin{array}{l}\text { Second } \\
\text { quarter }\end{array}$ & 11.22 & 5.62 & 7.35 \\
$\begin{array}{l}\text { Third } \\
\text { quarter }\end{array}$ & 15.38 & 5.38 & 8.24 \\
$\begin{array}{l}\text { Fourth } \\
\text { quarter }\end{array}$ & 9.25 & 3.25 & 5.36 \\
\hline
\end{tabular}

Table 1 shows the statistics of mobile e-commerce marketing platform based on WAP and WLAN in trading company, we can obtain the total sales of three sale channels. It can be seen from table that the performance of mobile e-commerce platform is more excellent than the internet. 


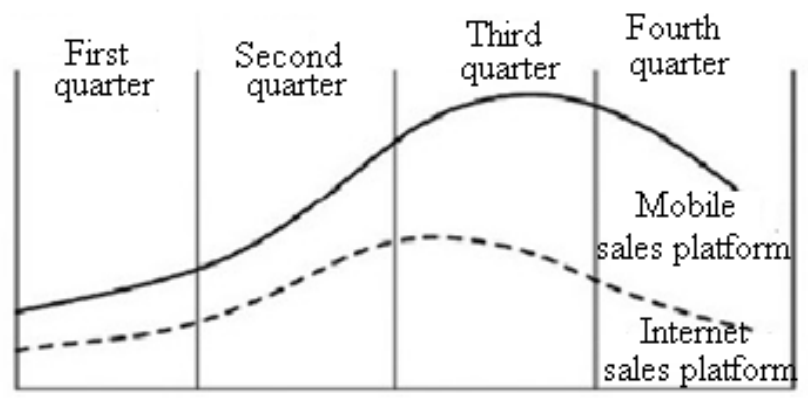

Fig.6: Analysis of the operation stability of electronic commerce platform

Figure 6 shows the operation stability analysis of e-commerce platform, which carries out examination from the use of flow and the transmission fluency of package [13]. It can be seen from the chart that in the four sales quarters, the internet and mobile sales end run smooth, there are no big fluctuations, and this shows that the system is reliable.

\section{Summary}

(1) Based on the WAP mobile shopping model, this paper designs the multiple variables autoregressive conditional heteroscedasticity model of consumer information positioning, the model uses PDA code to carry on localization for the users, and the use of $F$ test inspects on the significance of user data optimization.

(2) Through the system test, we found that this system can satisfy the demand of consumers shopping whenever and wherever possible, and system operation is not only more stable, but also can improve the company's sales performance, which provide reference data for the enterprise to develop a reasonable marketing strategy.

(3) The system is extended in a large range, which is still to be technology research. With the launch of $4 \mathrm{G}$ mobile services, more mobile communication technology can be used to e-commerce marketing platform, which provides more impetus for the development of e-commerce model.

\section{References}

[1] W.F. Shi, X.F. Mo. Study on supply chain finance based on e-commerce market. Chinese market, 2011(36): 34-36.

[2] W.J. Li, H.W. Ma. Research on supply chain financing mode based on B2B. Technology and management, 2011(4): 56-57.

[3] W.C. Li. Study on electronic commerce credit system in China. E-government, 2012(4): 112113.

[4] L.M. Guang. The information sharing in the construction of credit system. Chinese financial, 2012(2): 35-36.

[5] K.Y. Yang. The construction of e-business information ecosystem [J]. Information science, 2014(3): 78-79.

[6] B.W. Li, Y. Xu. Study on network information ecological chain taking Taobao and Tencent paipai as example. Information theory and practice, 2013(9): 78-80.

[7] B.W. Li, Y. Xu, C.L. Wei. Study on shopping website network information ecological chain in China. Modern library and information technology, 2013(9): 102-103.

[8] X.Q. Zhang. Discussion on WLAN access network construction. Value engineering, 2010(28): 45-46.

[9] H. Wang, F. Peng. The development of mobile world -- China mobile communication technology review and prospect. Telecom industry in China, 2007(11): 98-99.

[10] D.L. Zheng, X.L. Chen, S.T. Li. Reducing 3G user terminal energy consumption method in idle mode. Communication technology, 2012(4): 56-57.

[11] P. Shao, Y.S. Wu, X.H. Wen. Deployment and optimization of WLAN hot spots in the wireless urban construction. Telecommunication technology, 2011(11): 45-46. 
[12] Q. Duan, Y.T. Wang. Study of WLAN optimization. Telecommunication engineering technology and standardization, 2011(4): 89-90.

[13] Y. Tan. The analysis of operators WLAN optimization case. Telecom technology, 2011(7): 112-113. 